\title{
Smart Hair Salon Management System
}

\author{
Ms. Jadhav Vaishali ${ }^{1}$, Ms. Kumthekar Aarti V. ${ }^{2}$ \\ Student E\&TC Department, Dr. Daulatrao Aher College of Engineering, Karad, India ${ }^{1}$ \\ Assistant Prof. E\&TC Department, Dr. Daulatrao Aher College of Engineering, Karad, India ${ }^{2}$
}

\begin{abstract}
Nowadays, there is rapid need of automation to reduce human efforts and increase the work efficiency as everyone knows the importance of booming technology in many areas. As early methods of hair salon management systems are time consuming and incompetent so most probably these are neglected. Here the total salary of the workers in the salon and customer details are not properly recorded hence human efforts are more required. Therefore, proposed system known as "smart hair salon management system" which helps to overcome these drawbacks. The proposed system helps both the customer and owner to maintain the salon records in particular format. Based on the customer's entry as well as his/her registration, worker provides service to the respective customer according to their demand. Similarly, the process continues and queue is created. The type of queue formed is basically the principle of "First in First Out" (FIFO) strategy.
\end{abstract}

Keywords: Management, Customer, Worker, Hair Salon.

\section{INTRODUCTION}

The 21st century is said to be century of inventions, century of development, century of globalization because no one can end up the day without using any kind of embedded system products. It makes human life very smarter and to feel comfortable. Being a salon client today is inconvenient. The customer have to remember that the customer need to make an appointment, then hope he or she remember during business hours, and finally scramble to find the phone number and take time out of his or her busy day to make the call. And never mind finding user reviews of local salons, tracking those down somewhere on the web is a headache that most don't even attempt.

This is the experience of countless salon-visitors every day. As traditional methods of hair salon are inefficient, therefore proposed system is known as "smart hair salon management system" is considered here. The proposed system is based on embedded system. In this system, first the customer messages or call to the salon then worker at the salon accepts this message or call. Worker first calculates how many customers are waiting as well as predefined time for particular activity to give reply of that message. When the customer comes in particular given time, worker give service to it according to their demand. Similarly, the process is continues and queue is formed based on the functions. In this proposed system Microcontroller AT89c51 is used as a main control element. LCD is used to display information regarding salon schedule. RTC is used for giving current time.4x 4 keyboard is used to assign particular activities such as Hair Cutting, Shaving, Facial treatment etc. GSM Module is used for sending and receiving details of information. People can easily be reached through their handheld devices such as mobile phone irrespective of their location, Hence, there is need to develop a system that will combine the resources and reach people through short message service (SMS) using GSM module. PC is used for storing whole database. [1]

\section{LITERATURE REVIEW}

The traditional system of hair salon was manual and insecure because there was no any counting system of customers coming in the salon which creates sometimes major issues. The customer as well as the owner faces the problems.[2] These early systems are dependent on paperpencil systems for billing purpose that means the records of bills of customer and the workers working in their salon are in written form. The records may get wrong due to anyone's mistake. There is difficulty in maintaining records of all these tasks manually. Hence, proposed system is the best solution of avoiding all these problems. Salon manager are often responsible scheduling staff members, training new front desk workers. [3]

Since salon is a service sector, so the success of hair salon depends on the satisfaction of customer. The business of salon is totally dependent on customer satisfaction.

\section{PROPOSED METHODOLOGY}

The block diagram of the proposed system is as shown in Fig.1. the details of each block and working are as below.

A. Working Principle:

The functional block diagram consists of total eight blocks. The proposed system mainly consists of blocks such as Real Time Clock (RTC), 8051 Microcontroller (AT89c51), IR sensor, comparator, MAX 232, GSM Module, 16x2 LCD, PC, and 4x4 keypad. [7] 
Vol. 4, Special Issue 2, January 2017

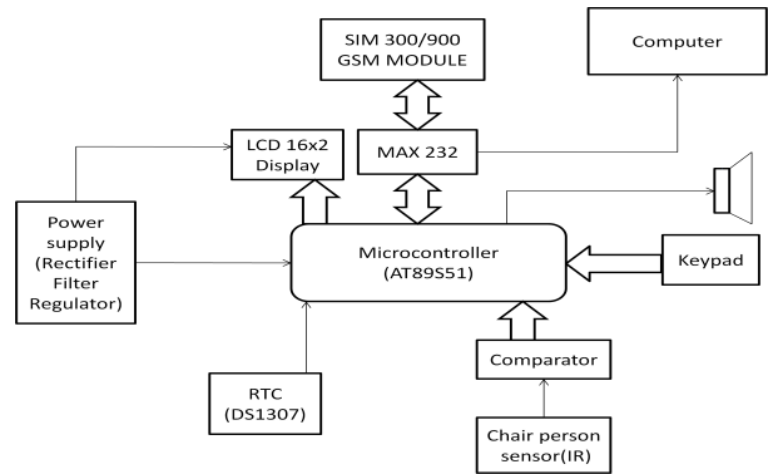

Fig 1: Block Diagram of the proposed system

At start, all peripherals are initializing their working. In this, RTC is used to give current timing of particular instant. All the functions in the salon are assigned to each particular key of keypad. When customer call or messages to the salon the worker at the salon accepts this message or call and reply back by calculating how many customers are waiting and total of predefined time for respective activity plus current time given by RTC. And these details are given as an input by microcontroller. The messages regarding salon schedule will be display on LCD as well as LCD display is used for displaying messages such as "Salon is closed" or any other. The GSM module is used for sending and receiving of information during normal working. And according to customer demand queue is formed and in PC the entire database will be store.

\section{B. Hardware Details:}

\section{(a) Microcontroller:}

AT89c51 microcontroller is used as a low-power, high performance CMOS 8-bit microcontroller with 4Kbytes of in-system programmable Flash memory. The device is created using Atmel's high density non-volatile memory technology and is compatible with the industry-standard 80C51 instruction set and pin out. The on-chip Flash gives permission to the program memory to be reprogrammed in-system or by a conventional non-volatile memory programmer. By combining a versatile 8-bit CPU with insystem programmable Flash on a monolithic chip, the Atmel AT89c51 is a powerful microcontroller which gives a highly-flexible and cost-effective solution to many embedded control application. The Idle Mode stops the Central processing unit (CPU) while allowing the RAM, timer/counters, serial port, and Interrupt system to continue functioning.

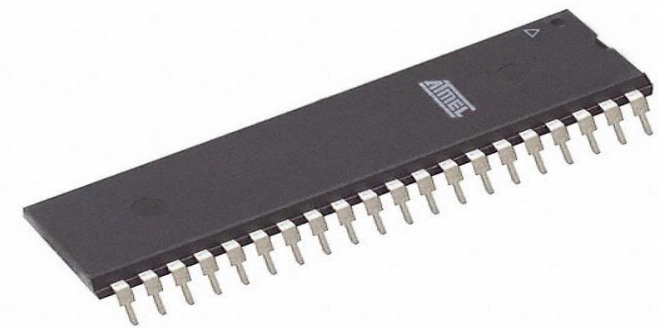

Fig.2. AT89C51 Microcontroller
The Power-down mode saves the RAM contents but freezes the oscillator, and it also disables all other chip functions until the next external interrupt or hardware reset.[4]

Features of AT89c51 microcontroller:

Compatible with MCS-51 products

8 bit CPU optimized for control application.

Address bus is of 16 bits.

Program external ROM is of 64KB.

In-System Programmable (ISP) Flash Memory is of $4 \mathrm{~K}$ Bytes.

Operating Range is from $4.0 \mathrm{~V}$ to $5.5 \mathrm{~V}$

Three-level Program Memory Lock

128 x 8-bit Internal RAM, 32 Programmable I/O Lines

Two 16-bit Timer/Counters

(b) GSM (Global System for Mobile Communication) Module:

GSM is mobile communication modem. It stands for global system for mobile communication. GSM modem is a specialized type of wireless modem. A GSM modem accepts a SIM card and operates just like a mobile phone because it is wireless network. A GSM modem works as like of the dial-up modem.

GSM module (SIM 900) is used to send \& receive the SMS from/to user. It is an AT command supportable serial communication module with 9600 default band rate. It works over the band of $900 \mathrm{MHz}$ to $1800 \mathrm{MHz}$.[8]

(c) MAX 232:

It is a logic level converter $\&$ it converts TTL logic to 232 \& vice versa. It is used to interface microcontroller with GSM. It is designed by Maxim integrated products, this IC is widely used in RS232 communication system in which the conversion of voltage level is required to make TTL device to be compatible with PC serial port and vice versa. MAX232 used in 16 pin DIP packets. MAX232 requires minimum 4 external capacitors. The capacitors are used depending upon the application.

(d) LCD (Liquid Crystal Display):

LCD (Liquid Crystal Display) screen is an electronic display module and plays as an important role in a wide range of applications. A $16 \times 2$ LCD display is very commonly used in various devices and circuits. These modules are used over seven segment LED's and other multi segment LED's.

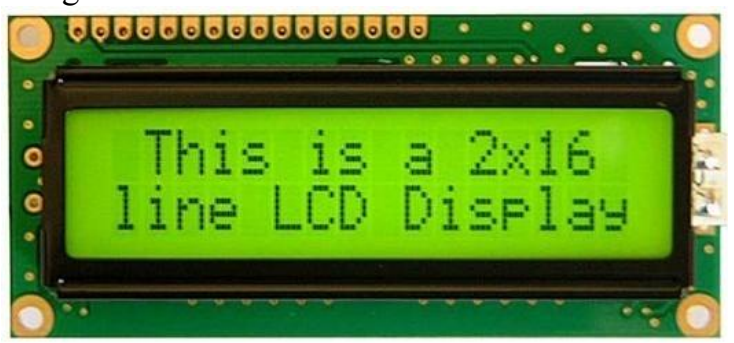

Fig.3. LCD Display 
A $16 \mathrm{X} 2 \mathrm{LCD}$ that name indicates it can display 16 characters per line and there are 2 such lines. In LCD each character is displayed in $5 \times 7$ pixel matrix. The LCD display takes place varying amounts of time to accomplish the functions. LCD bit 7 is monitored for logic high (Busy) to ensure the display is not overwritten. LCD's are economical, easily programmable; they have no limitations of displaying special \& even custom characters, animations and so on [5].

\section{Features:}

Display: 16 characters X 2 lines

Backlight: Yellow.

Operating Temperature: $00 \mathrm{c}$ to $500 \mathrm{c}$.

Operating Voltage: $4.5 \mathrm{~V}$ to $5.5 \mathrm{~V}$.

Backlight Voltage: 5.0V (100mA).

\section{(e) Personal Computer:}

A personal computer (PC) is a general purpose computer whose size, capabilities and price make it feasible for individual use. The system comprises primarily of a PC running the Graphic User Interface (GUI) application through matrix laboratory software (MATLAB).

(f) RTC (Real Time Clock):

RTC provide required time and date in many applications such as clock, staff attendance system and alarm etc that keep track on current time and provide consistent result to performed task. In RTC chip A0, A1, A2 are address pins, VCC and GND are supply and ground pins respectively. VBT is a battery power supply pin.[6]

\section{Software Details:}

(a)Keil Compiler:

The Keil Compiler for the microcontroller is most popular compiler in the world. It provides more features than another $8051 \mathrm{C}$ compiler available today. The C51 compiler allows you to write 8051 microcontroller applications in $\mathrm{C}$ that, once compiled, have the efficiency and speed of assembly language. The interfacing programs are executed by using Keil Compiler.

(b)Proteus 8 Professional:

Proteus is software for microprocessor simulation, schematic capture, and printed circuit board (PCB) design. It is developed by Lab center Electronics. Proteus 8 is best simulation software for various designs with microcontroller. It is mainly popular because of availability of almost all microcontrollers in it. So, it is a handy tool to test programs and embedded designs for electronics hobbyist. You can simulate your programming of microcontroller in proteus 8 simulation software.

(c)C Programming:

$\mathrm{C}$ is a set of language extensions for the $\mathrm{C}$ Programming language by the $\mathrm{C}$ Standards committee to address commonality issues that exist between $\mathrm{C}$ extensions for different embedded systems. Historically, embedded C programming requires nonstandard extensions to the $\mathrm{C}$ language in order to support exotic features such as fixedpoint arithmetic, multiple distinct memory banks, and basic operations. In 2008, the C Standards Committee extended the $\mathrm{C}$ language to address these issues by providing a common standard for all implementations to adhere to. It includes a number of features not available in normal $\mathrm{C}$, such as, fixed-point arithmetic named address spaces, and basic I/O hardware addressing Embedded $\mathrm{C}$ uses most of the syntax and semantics of standard C, e.g. main function, variable definition, data type declaration, conditional statements (if, switch, case), loops (while, for), functions, arrays and strings, structures and union, bit operations macros, etc.

\section{FLOWCHART}

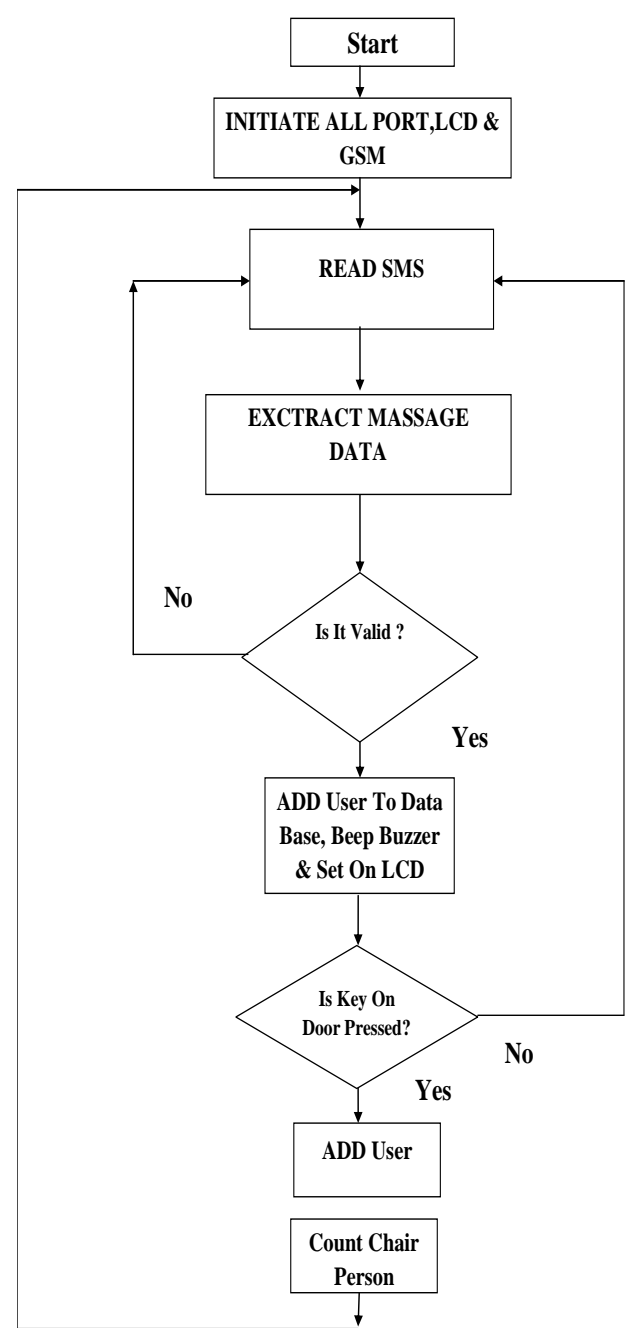

Fig.4. Flow Chart

\section{CONCLUSION}

The proposed system seems to be far better and efficient in terms of technology and integration point of view. 
Application is easy to use, time saving and efficient to give service to the clients of salon. The system is useful to both owner and customer which is electronics storage of all required data. The system is real time system which does not require human efforts in calculating bills and maintain customer details. The security in salon management system can be maintained by using small camera. The system can use battery backup when there is no power supply. For users authentications the password system can be implemented. Instead of keyboard, touch screen can be implemented.

\section{REFERENCES}

[1] Yonan Getachew, "Design and implementation of Crisis and Emergency Reporting and Response system using SMS" Addis Ababa University Digital Library, June 2009

[2] L.Naismith, P.Lonsdale, G.Vavoula, M.Sharples, "Literature Review in Mobile Technologies"

[3] nevonprojects.com/salon-management

[4] A book of "The 8051 Microcontroller and "Embedded Systems" by Mohammad Ali Mazidi.

[5] www.ebay.in/./LCD

[6] www.engineersgarage.com

[7] www.parallax.com

[8] www.en.wikipedia.org/wiki/GSM 